\title{
DURABILITY OF GLASS FIBER REINFORCED MORTAR
}

\author{
A. A. M. Badawy, M. H. Seleem, E. M. Y. Abdin, A. H. H. El- Safory \\ Materials Engineering Dept., Faculty of Engineering, \\ Zagazig University, EGYPT
}

\begin{abstract}
In this work, the durability of glass fiber reinforced mortar, GFRM, was experimentally investigated. The evaluation was based on the performance of the composite under three mechanical tests (compression, indirect tension and flexural). The GFRM specimens were exposed to four-environmental attack. These include air, water, chloride and sulfate. The specimens were tested after $28,180,360$ and 540 days. The effect of fiber volume fractions, $\left(V_{f}=0,1,2\right.$ and $\left.3 \%\right)$ was considered. The effect of using sulfate resistant cement and addition of $10 \%$ silica fume to the ordinary Portland cement on the durability of the GFRM was undertaken. Test results indicated that the addition of glass fiber has a small effect on the compressive strength of GFRM specimens. The presence of glass fiber in the cement-based mortar enhanced the relative compressive strength of the composite stored in sulfate. There is a general increase in the tensile and flexural strengths with increasing fiber volume fraction. The addition of $10 \%$ silica fume enhanced the compressive and tensile strengths of the specimens stored in water media at all ages but for specimens stored in sulfate it enhanced up to 180 days and after that they decreased. Sulfate resistant cement enhanced the compressive and tensile strengths of GFRM stored in sulfate media compared to those specimens stored in water media.

يهدف البحث إلي تقييم الديمومة للمونة الأسمنتية المسلحة بالألياف الزجاجية عند تعرضها لأوساط تخزين مختلفة

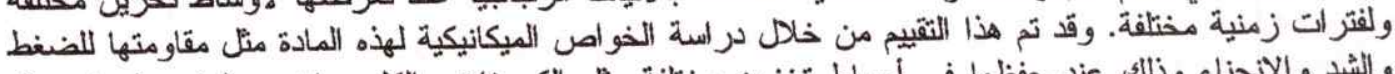

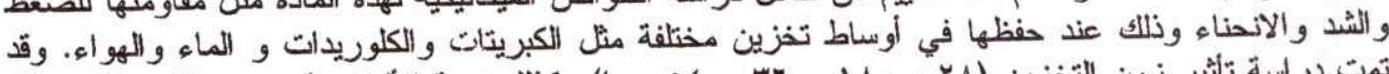

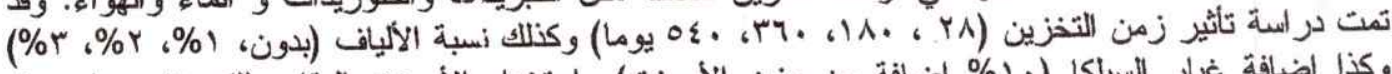

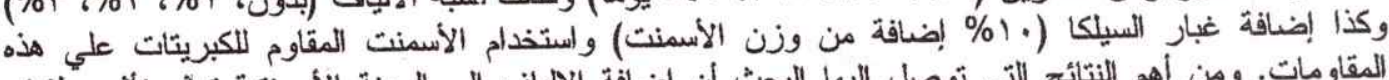

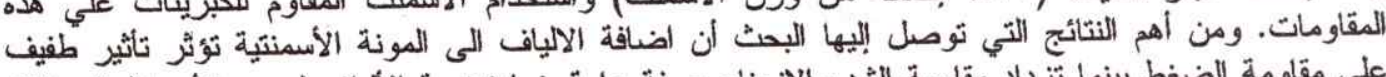

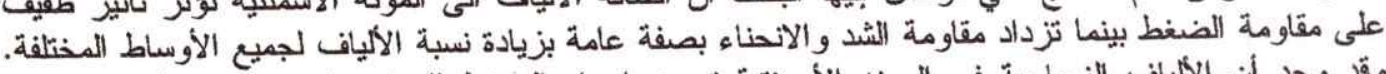

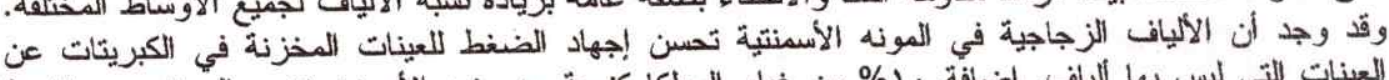

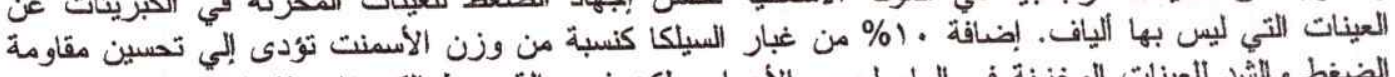

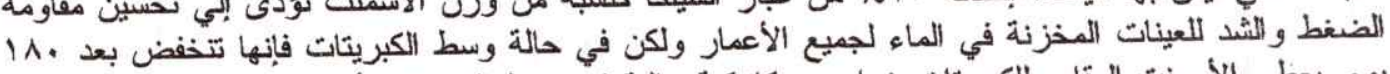

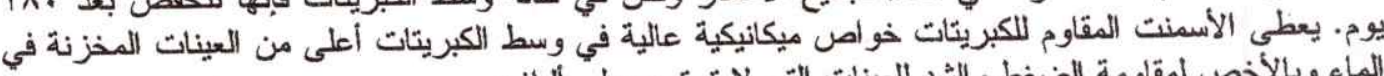

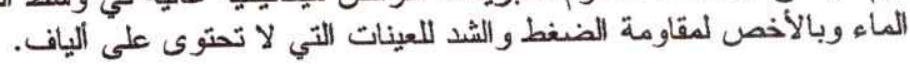

Keywords: Cement bases mortar, Glass fiber, Durability, Mechanical properties.

\section{INTRODUCTION}

Durability is one of the major factors that classify concrete and mortar as a very important construction material. Several investigations had been reported the main factors controlling durability of cementitious materials [1-9]. They mentioned that, the durability of concrete or mortar depends up on: i) conditions of exposures (type and concentration of aggressive media in the concrete environment and also exposure time, ii) the permeability of concrete (the rate at which chemicals penetrate into the solia), and iii) the compositions of cement such as, the content of tricalcium aluminates $\left(\mathrm{C}_{3} \mathrm{~A}\right)$ and the amount of calcium hydroxide, $\mathrm{Ca}(\mathrm{OH})_{2}$, formed during the hydration process. One of the major problems of cement- based materials is the brittle nature of failure which occurs under tensile and flexural stress systems or impact loading in the construction industry. Therefore, several types of fibers have been developed for the use in concrete structures. The mechanical behavior of fiber reinforced cement- based materials has been the subject of many researches during the last five decades [10-12]. Glass fiber reinforced cement is still a relatively new material and developments are taking place at a rapid rate, which affect the materials, manufacture, properties and applications.

The presence of sulfate or chlorides ions in water leads to aggressive behavior towards composites because some constituents of the cement can inter into deleterious chemical reactions with sulfate and 
chlorides. Super-sulfate cement, such as slag cement or addition of silica fume to ordinary Portland cement showed resistant to a variety of aggressive agents [13-18].

The main purpose of this thesis is to get a general finding for the best potentiality of GFRM from the view point of durability. Mechanical properties (compression, tension and flexural strengths) will be measured with taking into consideration the effect of changing the constituents of the GFRM such as fiber volume fractions and cementitious materials with using different storage media over various storage times.

\section{EXPERIMENTAL PROGRAM}

The experimental program suggested for the present experimental program is illustrated in Table 1 . Three specimens were tested for each combination of test parameters which leads to the fabrication of 792 test specimens. The constituent materials used in the fabrication of all specimens were locally available materials except the alkali-resistant glass fiber, NEGARG fiber. The ingredients of the mixes used in this study were cement, sand, water and high range water reducing admixture (super-plasticizer). Natural siliceous sand with $100 \%$ passing ASTM sieve No. 4 was used. Two types of cement were used in this work. The first was type I ordinary Portland cement, OPC. The second was type II sulfate resistant cement, SRC. Silica fume, SF, with 95 percent $\mathrm{SiO}_{2}$ and $18 \mathrm{~m}^{2} / \mathrm{gm}$ specific surface area was used. Silica fume was added to the OPC by $10 \%$ of cement weight. The water/cement ratio, W/C, for all mix was 0.35 . The properties of the used glass fiber are listed in Table 2. The fibers were supplied in the form of strands of $25 \mathrm{~mm}$ length and 13-20 $\mu \mathrm{m}$ diameter. High range water reducing admixture, Super-plasticizer, was used to overcome the loss of workability due to the presence of fibers and SF. The fiber content, $\mathrm{V}_{\mathrm{f}} \%$, investigated in this work was 0,1 , 2 , and $3 \%$ by volume of cement based mortar as illustrated in the experimental program given in Table 1. Magnesium sulfate was chosen to represent the corrosive media for sulfate resistance tests. Sodium chloride was chosen to represent the corrosive media for chloride resistance tests. The concentration of the two salts was $7 \%$. The mix proportions of all tests specimens were 2: $1: 0.35$ (cement: sand: water/cement).

Cube specimens $(70.7 \mathrm{~mm})$ were prepared for the compression test, cylinders specimens $150 \mathrm{~mm}$ height and $75 \mathrm{~mm}$ diameter were prepared for the indirect tension test and beam specimens of $40 \mathrm{~mm} \mathrm{x}$ $80 \mathrm{~mm}$ cross section and $400 \mathrm{~mm}$ total span were prepared for flexural tests. The three point bending configuration was used for the flexural test with the loaded span of $320 \mathrm{~mm}$. Dry materials were weighted. The sand and cement were mixed by hand in the dry state for 2 minutes until they were thoroughly blended. Then the water was added after blending with the required quantity of superplasticizers. Finally the short glass fibers were gradually added to the wet mix and the composite was mixed by hand and kept carefully to minimize fiber damage. The surface of all specimens was smoothly trawled immediately after casting. The specimens were retained in the moulds at room temperature for 24 hours before de-molded. All specimens were cured in water for 7 days after that they transported to the storage media (air, water, chloride $(7 \% \mathrm{NaCL})$ or sulfate $\left.\left(7 \% \mathrm{MgSO}_{4}\right)\right)$ to the required duration $(28,180,360$ and 540 days).

\section{RESULTS AND DISCUSSION}

\section{Effect of Fiber Volume Fraction}

The effect of fiber volume fractions on the compressive strength of GFRM is shown in Fig. 1 for specimens stored in air, 1(a), water, 1(b), chloride, 1(c) and sulfate, 1(d).

For specimens stored in air, Fig. 1(a), it is clear that the compressive strength increases with increasing $V_{f}$ up to $1 \%$ then decreases to reach a value less than that of control specimens. This is because the increase in fiber volume fraction, manufactured by the premixing technique, increases the matrix porosity and thus decreases the matrix compressive strength. Thus we can conclude that, the composite compressive strength is a matrix control property. The figure also shows an increase in the compressive strength with increasing storage age but with a decelerating rate.

Table 1: The experimental program suggested for this work

\begin{tabular}{|l|l|l|l|}
\hline $\begin{array}{c}\text { Cementitious } \\
\text { materials }\end{array}$ & $\begin{array}{c}\text { Fiber volume fractions, } V_{\mathbf{f}} \\
\%\end{array}$ & \multicolumn{1}{|c|}{$\begin{array}{c}\text { Storage media } \\
*\end{array}$} & \multicolumn{1}{|c|}{ Storage ages, days } \\
\hline $\mathrm{OPC}$ & $0,1,2,3$ & $\mathrm{~A}, \mathrm{~W}, \mathrm{C}, \mathrm{S}$ & $28,180,360,540$ \\
\hline $\mathrm{OPC}+10 \% \mathrm{SF}$ & 0,2 & W, S & $28,180,360$ \\
\hline $\mathrm{SRC}$ & 0,2 & W, S & $28,180,360$ \\
\hline$* \mathrm{~A}:$ Air & W: Water & C: Chloride $\quad$ S: Sulfate \\
\hline
\end{tabular}


Table 2: Properties of the used glass fiber

\begin{tabular}{|l|l|}
\hline \multicolumn{1}{|c|}{ Property } & \multicolumn{1}{c|}{ Value } \\
\hline Strand tensile strength & $1.4 \mathrm{GN} / \mathrm{m}^{2}$ \\
\hline Strain at breaking point & $2 \%$ \\
\hline Density & $2.7 \mathrm{~g} / \mathrm{cm}^{3}$ \\
\hline Young's modulus & $74 \mathrm{GN} / \mathrm{m}^{2}$ \\
\hline Filament diameter & $13-20 \mu \mathrm{m}$ \\
\hline Softening point & $830^{\circ} \mathrm{C}$ \\
\hline $\begin{array}{l}\text { Coefficient of thermal } \\
\text { expansion }\end{array}$ & $9 \times 10^{-6} 1 /{ }^{\circ} \mathrm{C}$ \\
\hline Weight loss & $0.8 \%$ \\
\hline Tensile strength retention & $75 \%$ \\
\hline
\end{tabular}

For specimens stored in water, Fig. 1(b), similar behavior for the effect of fiber volume fraction on the compressive strength is observed as in air. Also, the figure shows a notable increase in the compressive strength with increasing storage age. This may be attributed to the continuity of hydration process as the specimens still stored in water [19]. The trend in chloride is also similar to that in air and water with some difference at $\mathrm{V}_{\mathrm{f}}$ equals $1 \%$. At this percent of $V_{f}$ there is no effect on the compressive strength. With further increase in $V_{f} \%$, the compressive strength decreases to reach $80 \%$ of that of the control specimens at $V_{f}$ equals $3 \%$ at storage age of 28 days. The enhancement in the compressive strength with increasing storage age is predominant. The specimens stored in sulfate show a different trend where the compressive strength is almostely unchanged with increasing $\mathrm{V}_{\mathrm{f}} \%$ but small enhancement is observed at $V_{f}$ equals $2 \%$ for all storage ages.

After $V_{f}$ equals $2 \%$, the compressive strength decreases. The figure also shows a marginal effect to the storage age on the compressive strength for all $V_{f}$ $\%$.

Figure 2 shows the effect of fiber volume fractions on the tensile strength of GFRM composite stored in air, Fig.2 (a), water, Fig.2 (b), chloride, Fig.2 (c), and sulfate, Fig.2 (d). All figures show a general increase in the tensile strength with increasing $V_{f} \%$, which confirms with many published works $[10,11]$.

The increase in the tensile strength of GFRM specimens with increasing fiber volume fraction may be attributed to increasing the factor responsible to carry the load, fiber, as well as increasing the bonding area between the matrix and fiber. Thus we can conclude that the tensile strength is fiber control property. The figure shows also that the tensile strength increased with increasing storage age for all $\mathrm{V}_{\mathrm{f}} \%$ considered.

The effect of fiber volume fractions on the flexural strength of GFRM specimens is illustrated in Fig. 3 for storage media of air, Fig. 3(a,) water, Fig. 3(b), chloride, Fig. 3(c), and sulfate, Fig. 3(d). It is clear that, the flexural strength increases with increasing fiber volume fraction for the different storage media and storage ages. This is because the flexural strength is fiber control property as the tensile strength. A little enhancement in the flexural strength is recorded with increasing storage age.

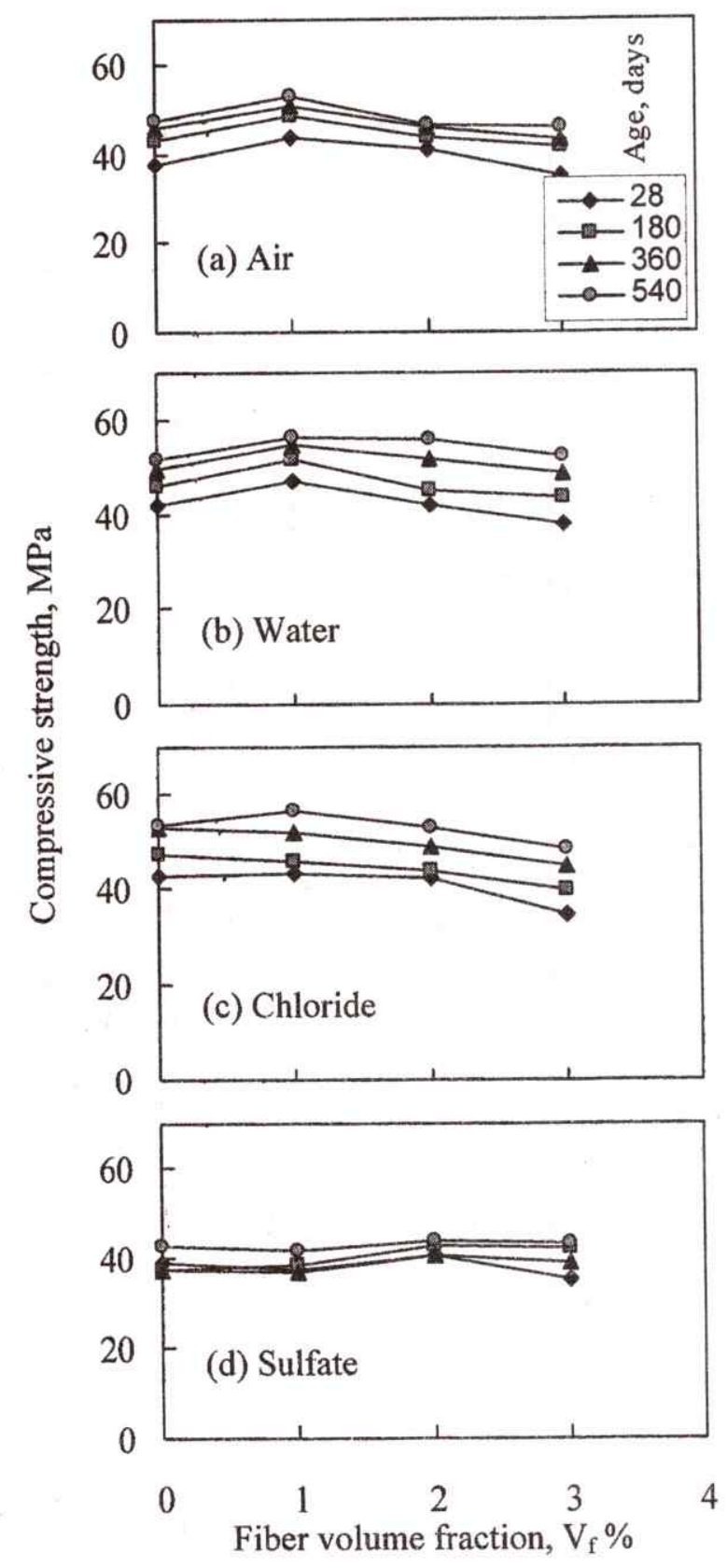

Fig.1 Effect of $V_{f} \%$ on the compressive Strength of GFRM specimens stored in
(a) Air
(b) Water
(c) Chloride and
(d) Sulfate 
For specimens stored in water as shown in Fig.3(b), the effect of storage age on the recorded flexural strength is small at $\mathrm{V}_{\mathrm{f}}$ equals $0 \%$ and $1 \%$. At $\mathrm{V}_{\mathrm{f}}$ equals $2 \%$ and $3 \%$, a considerable increase in the flexural strength is recorded $w$ ith increasing s torage age. This is because with increasing $\mathrm{V}_{\mathrm{f}}$, the contact surface area between fiber and matrix increases, thus the strength of this interface is very important for the

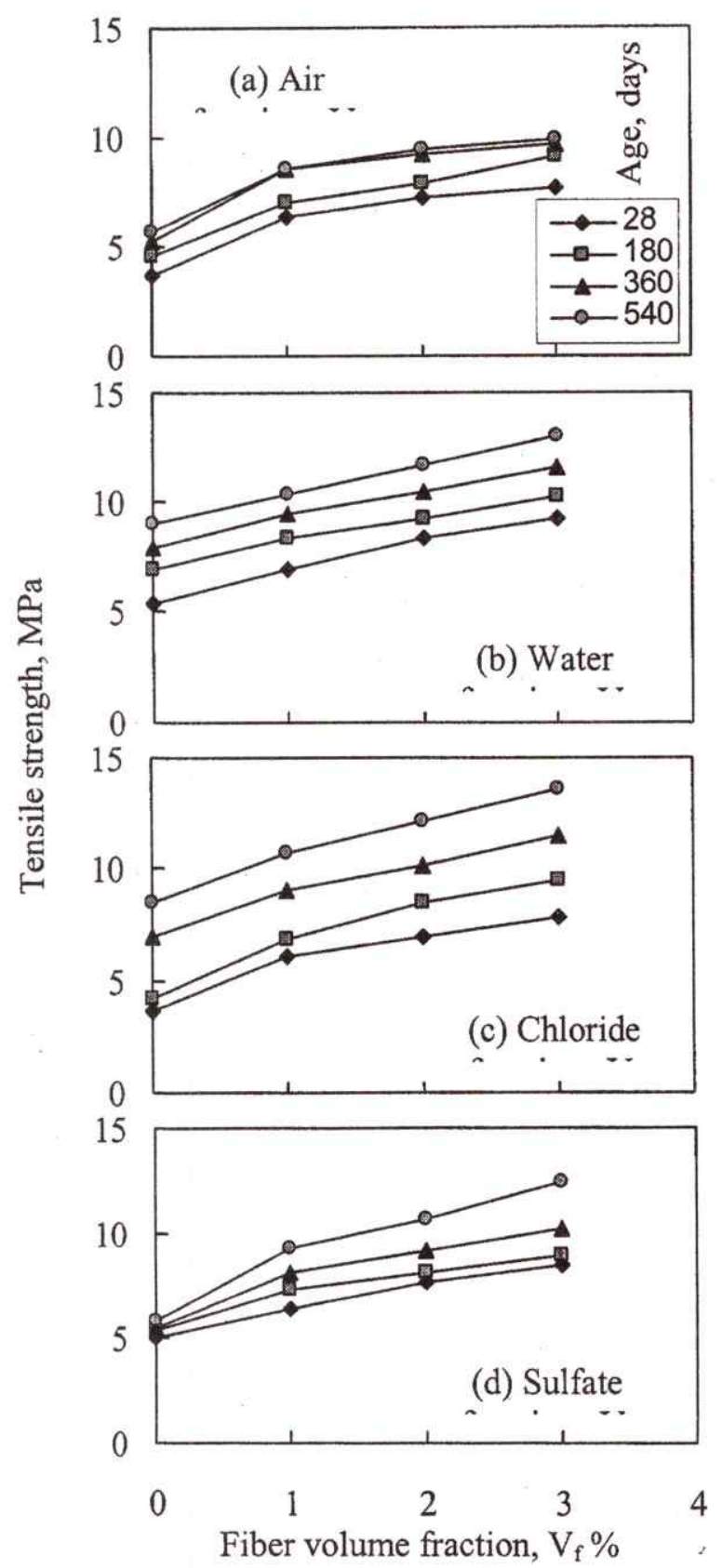

Fig.2 Effect of $V_{f} \%$ on the tensile strength of GFRM specimens stored in
(a) Air
(b) Water
(c) Chloride and
(d) Sulfate

responsibility of enhancing flexural strength. The continuity of c uring in water leads to the continuity of hydration process and thus increasing interface strength. Fig. 3(d) shows that there is no effect on the flexural strength of control specimens with increasing storage age up to 360 days.

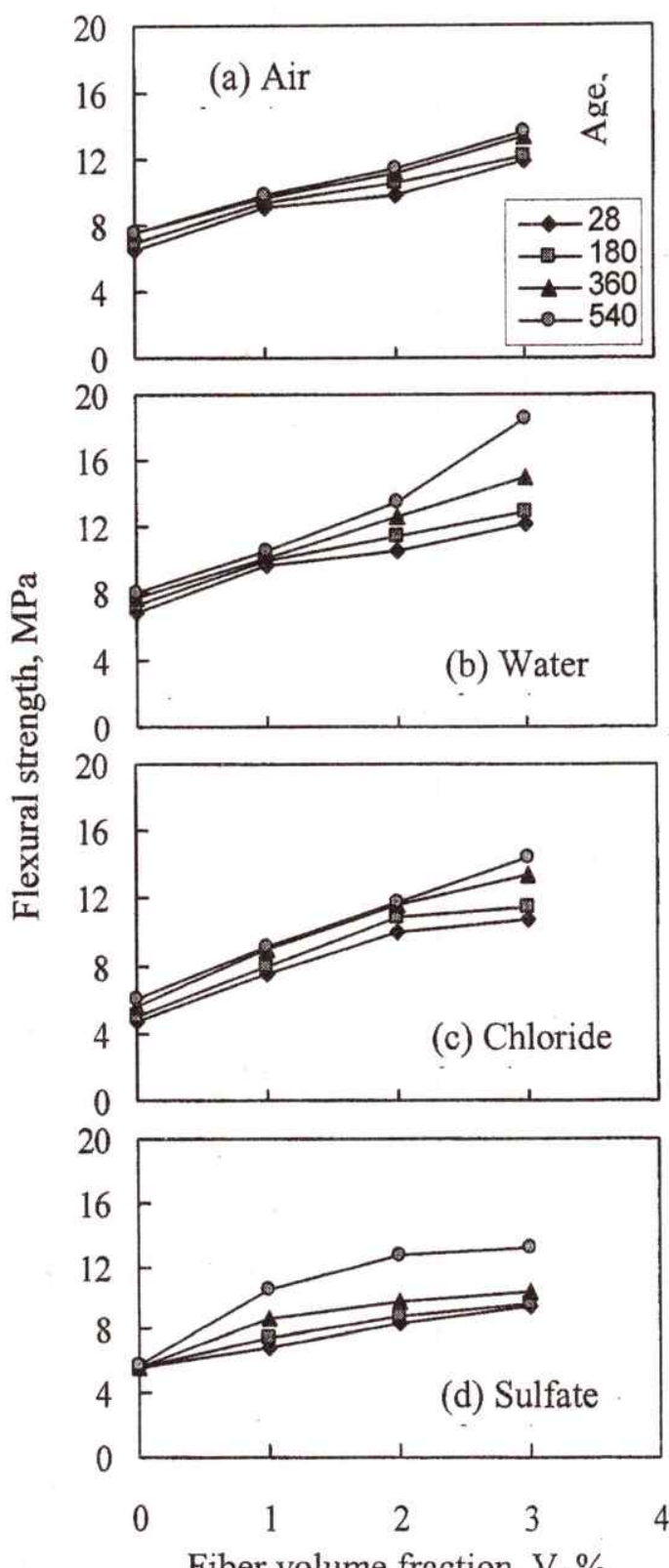

Fig.3 Effect of $V_{f} \%$ on the flexural strength of GFRM specimens stored in
(a) Air
(b) Water
(c) Chloride and
(d) Sulfate 


\section{Effect of Storage Media}

The effect of storage media on the relative compressive strength, $\sigma_{\mathrm{cm}} / \sigma_{\mathrm{cw}}$, of the GFRM composite is shown in Fig. 4 for different fiber volume fractions, $V_{f}=0 \% 4(a), V_{f}=1 \% 4(b), V_{f}=2 \%$ $4(\mathrm{c})$ and $\mathrm{V}_{\mathrm{f}}=3 \% 4(\mathrm{~d})$. Where $\sigma_{\mathrm{cw}}$ is the compressive strength of specimens stored in water and $\sigma_{\mathrm{cm}}$ is the corresponding value for specimens stored in the other media (air, chloride and sulfate) at the same storage age.

Based on the compression test results of GFRM specimens stored in different storage media for different storage ages, several points of interest $\mathrm{c}$ an be discussed. For the un-reinforced specimens, the specimens stored in chloride gave the highest compressive strength, while for the reinforced specimens by different $\mathrm{V}_{\mathrm{f}} \%$, the specimens stored in water gave the highest compressive strength. This may be attributed to that the hydration products, which fill the voids due to the presence of fibers, for the specimens stored in water have higher strength than that in the other media. The presence of chloride in the storage media for the control specimens accelerates the hydration process, which may be responsible for the higher strength of these specimens. For all $\mathrm{V}_{\mathrm{f}} \%$ considered, the relative compressive strength for specimens stored in air showed a general decrease with increasing storage age. This may be attributed to the incomplete hydration process of these specimens in the absence of its controlling parameter, water.

The specimens stored in sulfate media always result in the lowest relative compressive strength. This is because the hydration product, ettringite, in the sulfate media is weak and occupy a greater space than the original compounds causing expansion, disruption and cracking of the phase responsible for the composite compressive strength, matrix. The presence of glass fiber in the cement-based mortar enhances the relative compressive strength of the composite stored in sulfate. This is because, the presence of fiber leads to the formation of $\mathrm{v}$ oids in the matrix and with increasing $V_{f} \%$, these voids percent increase. The products of sulfate attack replace the air in these voids and thus somewhat enhances the matrix compressive strength.

The effect of storage media on the relative tensile strength, $\sigma_{\mathrm{tm}} / \sigma_{\mathrm{tw}}$, of the GFRM composite is shown in Fig. 5 for $V_{f}=0 \% 5(a), V_{f}=1 \% 5(b), V_{f}=2 \% 5(c)$ and $V_{f}=3 \% 5(d)$. Where $\sigma_{t w}$ is the tensile strengths of specimens stored in water and $\sigma_{t m}$ is the corresponding values for specimens stored in the other media at the same storage ages.

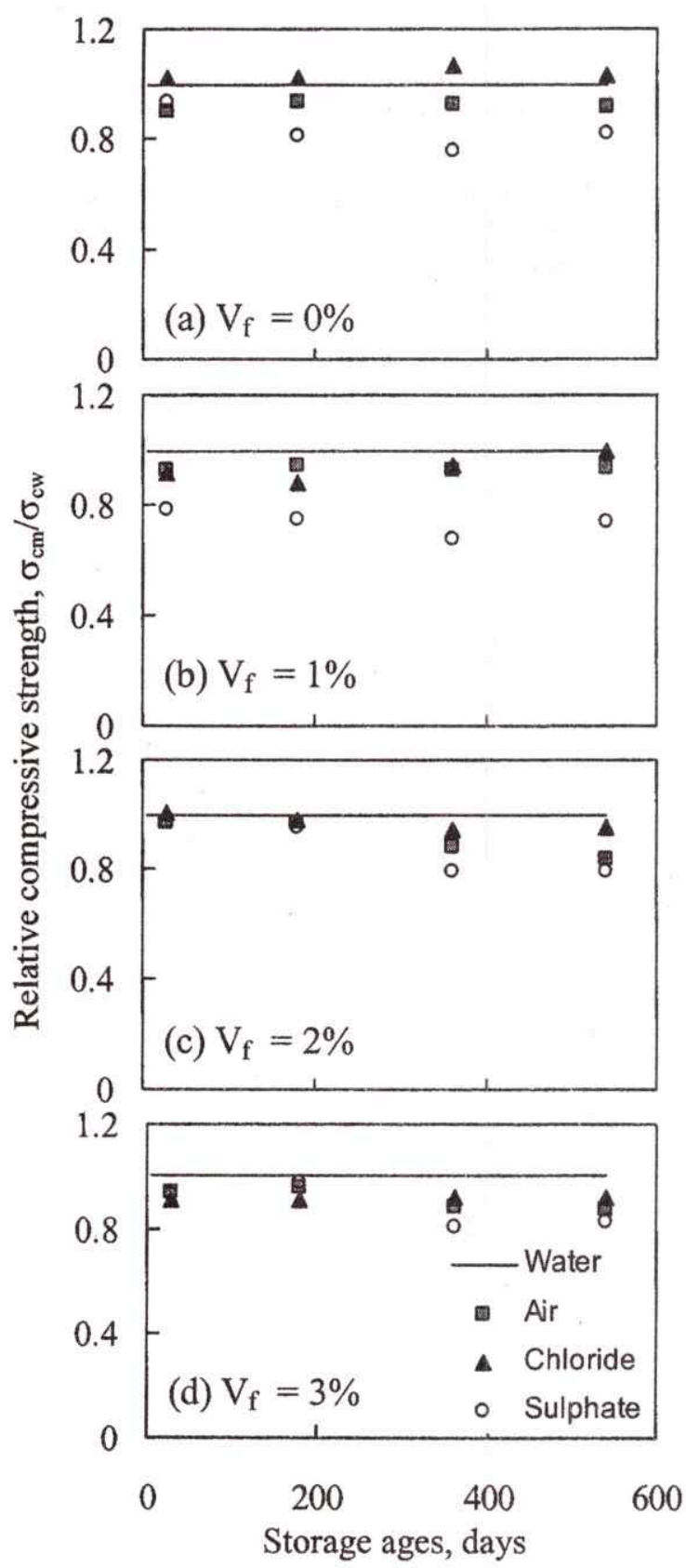

Fig.4 Relative compressive strength, $\sigma_{\mathrm{cm}} / \sigma_{\mathrm{cw}}$, against storage ages for:
(a) $\mathrm{V}_{\mathrm{f}}=0$
(c) $\mathrm{V}_{\mathrm{f}}=2 \%$ and
(b) $\mathrm{V}_{\mathrm{f}}=1 \%$
(d) $V_{\mathrm{f}}=3 \%$.

The points of interest from the results of tension test are the behavior of specimens stored in water, sulfate and chloride at early and later ages.

It was found that, at early ages, the specimens stored in water media have large tensile strength compared to that stored in sulfate and chloride media. On the other hand, at later age the tensile strengths of specimens stored in sulfate and chloride media are approximately e qual or little large than those stored in water media. 
This behavior can be explained as follows: The rate of hydration for specimens stored in water is fast at early ages and this rate decreases with time. On the other hand the sulfate and chloride media introduce acceleration of attack with increasing storage age. The results of such attack fill the voids in the composite due to the presence of fibers and thus improve the measured tensile strength.
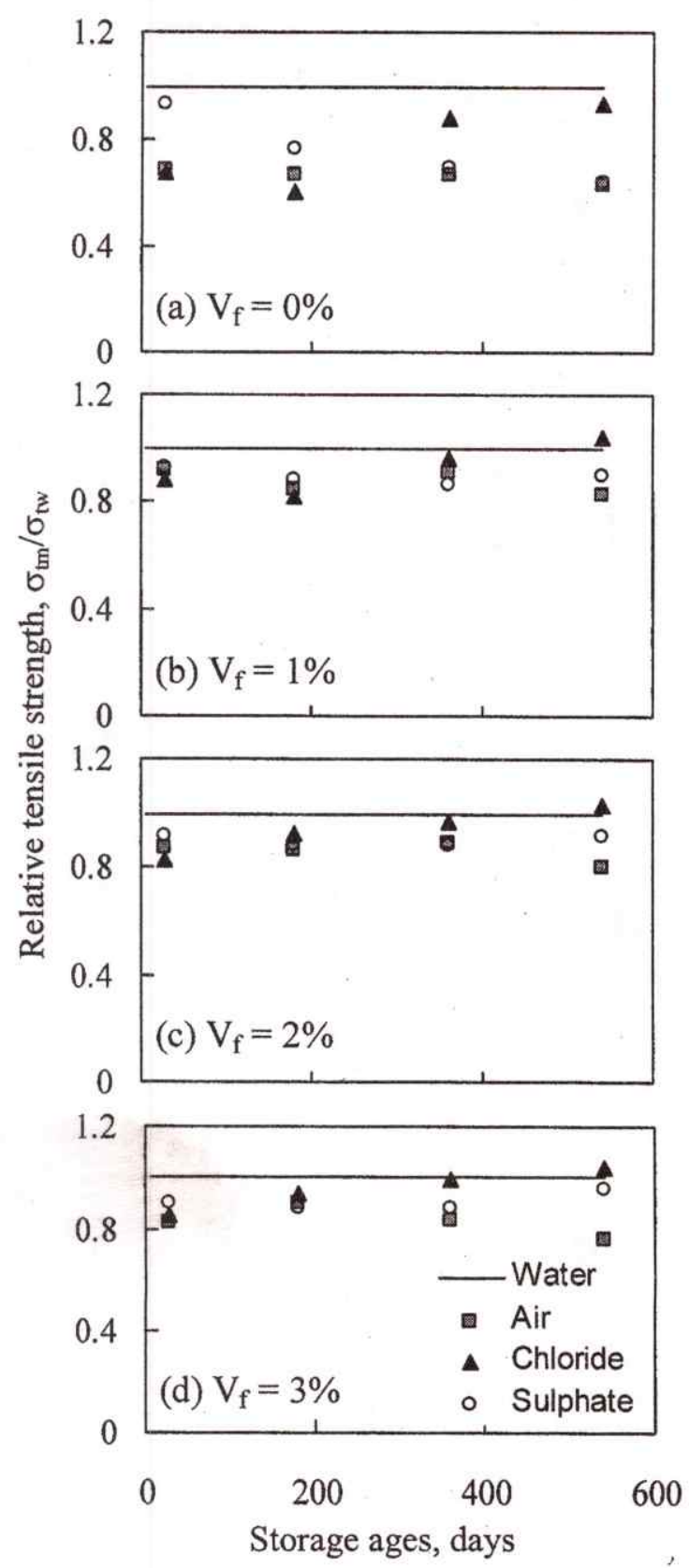

Fig.5 Relative tensile strength, $\sigma_{t \mathrm{tm}} / \sigma_{\mathrm{tw}}$, against storage ages for:
(a) $V_{\mathrm{f}}=0$
(c) $V_{\mathrm{f}}=2 \%$ and
(b) $\mathrm{V}_{\mathrm{f}}=1 \%$
(d) $V_{f}=3 \%$.

For specimens stored in air, it is clear that the rate of enhancement in the tensile strength with increasing fiber volume fraction is higher than that for specimens stored in water media. This can be attributed to the higher tensile strength of the control specimens stored in water.
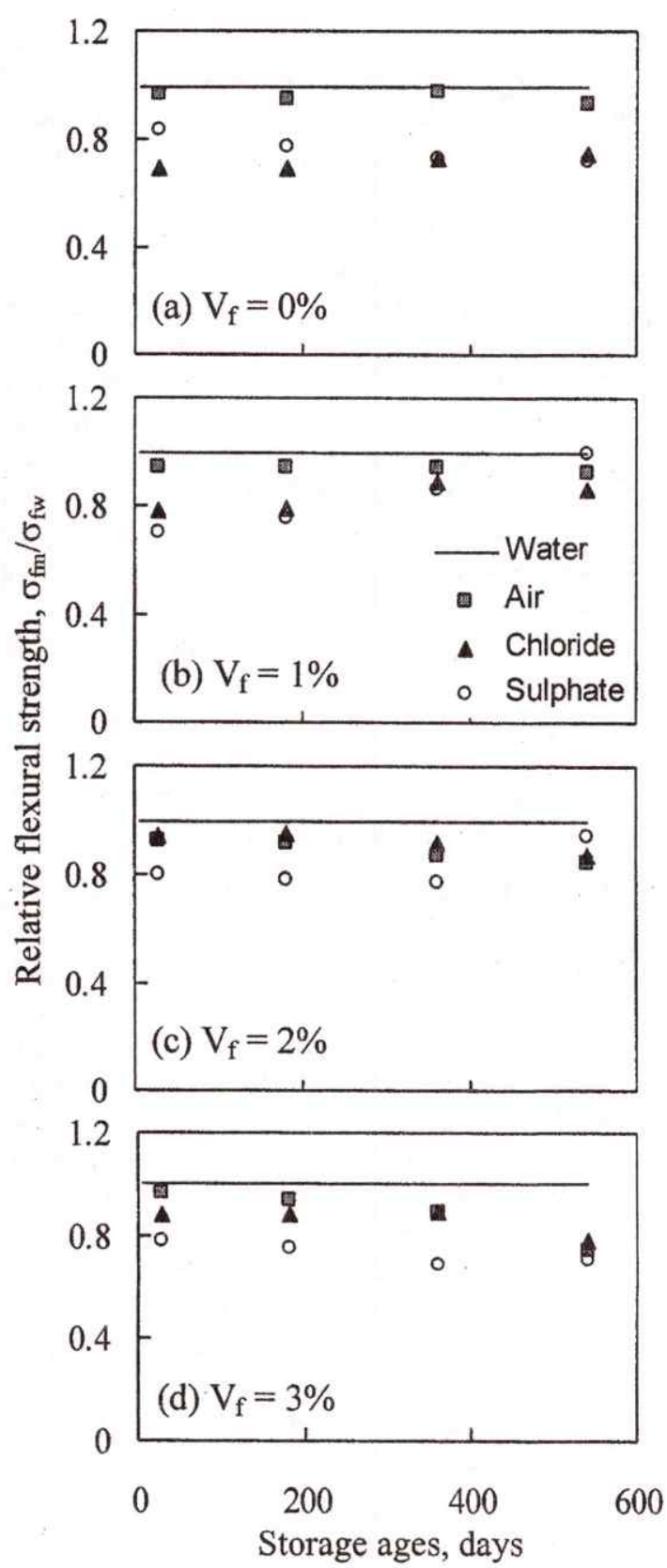

Fig.6 Relative flexural strength, $\sigma_{\mathrm{fm}} / \sigma_{\mathrm{fw}}$, against storage ages for:
(a) $\mathrm{V}_{\mathrm{f}}=0$
(c) $\mathrm{V}_{\mathrm{f}}=2 \%$ and
(b) $\mathrm{V}_{\mathrm{f}}=1 \%$
(d) $\mathrm{V}_{\mathrm{f}}=3 \%$. 
The effect of storage media on the relative flexural strength, $\sigma_{\mathrm{fm}} / \sigma_{\mathrm{fw}}$, of the GFRM composite is s hown in Fig. 6 for different fiber volume fractions, $V_{f}=0 \%$ $6(\mathrm{a}), V_{\mathrm{f}}=1 \% 6(\mathrm{~b}), \mathrm{V}_{\mathrm{f}}=2 \% 6(\mathrm{c})$ and $\mathrm{V}_{\mathrm{f}}=3 \% 6(\mathrm{~d})$. Where $\sigma_{f w}$ is the flexural strength of specimens stored in water and $\sigma_{\mathrm{fm}}$ is the corresponding value for specimens stored in the other media (air, chloride and sulfate) at the same age of storage. The points of interest reveal from this figure are that, the specimens stored in water $g$ ave the highest flexural s trength at all storage ages and for all $\mathrm{V}_{\mathrm{f}} \%$ considered. At the early storage ages, up to 180 days, the fiber reinforced specimens stored in sulfate gave the lowest flexural strength. For the un-reinforced specimens, the effect of storage media on the flexural strength is clear at all storage ages. For reinforced specimens, the effect of storage media on the flexural strength decreases. At later ages and large $V_{f} \%$, the effect of storage media is approximately finished. At such condition the fiber controls the flexural strength.

\section{Effect of Silica Fume (SF)}

Figures 7 to 9 show the effect of SF addition on the compressive, tensile and flexural strengths of the GFRM composite, respectively, stored in water and sulfate media at $\mathrm{V}_{\mathrm{f}}$ equals $0 \%$, Figs. (a), and $\mathrm{V}_{\mathrm{f}}$ equals $2 \%$, Figs. (b). The general trend is that, all strengths of the un-reinforced and reinforced

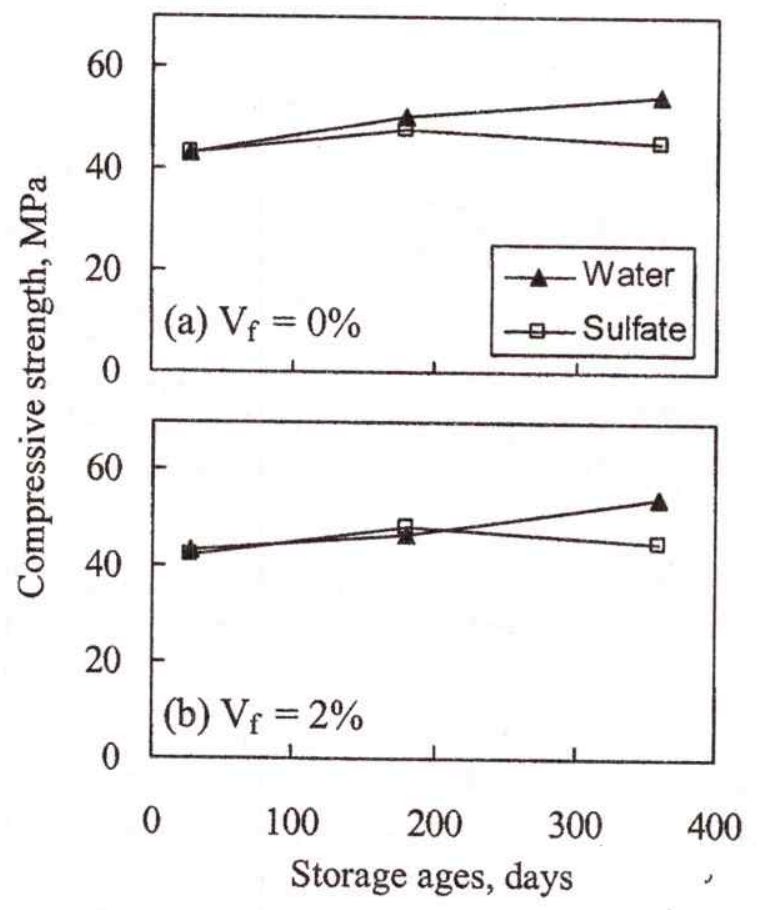

Fig.7 Compressive strength of GFRM composites against storage ages in presence of silica fume for:
(a) $\mathrm{V}_{\mathrm{f}}=0 \%$
and
(b) $V_{f}=2 \%$.

specimens stored in water increase with increasing storage age. On the other hand the specimens stored in sulfate show an enhancement in the compressive and tensile strengths up to 180 days. After that the strengths decrease from 180 to 360 days as shown in Figures.7 and 8. This can be explained as follow: At the first periods of exposure of specimens contain SF to magnesium sulfate solution; the reaction product of SF fills the pores between the cement particles. Where, SF reacts with the calcium hydroxide liberated from cement hydration results in the formation of secondary C-S-H which increases the strengths consequently. At the end of the test, 360 days, and after long period of exposure, the consumption of the amount of calcium hydroxide by SF provides an opportunity to magnesium sulfate to react more directly with the primary and secondary calcium silicate hydrate. This is followed by an increase in the decalcification and alteration of C-S$\mathrm{H}$ gel to $\mathrm{M}-\mathrm{S}-\mathrm{H}$ gel (non-cementitious product). This alternation r esults in softening of material [3]. So it can be concluded that, SF has lower performance in magnesium sulfate especially than that specimens without SF. This is confirmed by Bonen [3] and AlAmoudi et al [2].

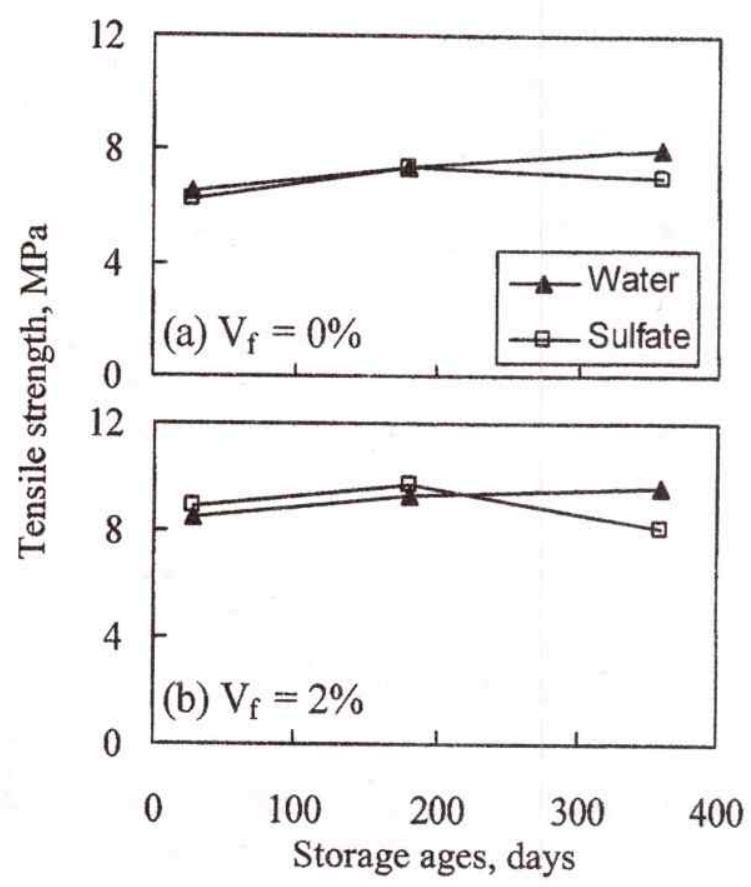

Fig.8 Tensile strength of GFRM composites against storage ages in presence of silica fume for:
(a) $V_{f}=0 \%$ and
(b) $V_{f}=2 \%$. 
It is also observed that the effect of SF on the enhancement of compressive and tensile strengths of specimens stored in sulfate media at 180 days is more pronounced for fiber reinforced specimens and is greater than those stored in water at the same $V_{\mathrm{f}} \%$. This may be attributed to the improvement in both the matrix and interface strength due to the presence of SF. The reaction products of SF with calcium hydroxide fill the voids that result from the presence of fiber and so enhance the composite action between matrix and fiber.

Figure 9 shows the effect of SF addition on the flexural strength of GFRM composite stored in water and sulfate media at $V_{f}$ equals $0 \%$, Fig. 9(a), and $V_{f}$ equals $2 \%$, Fig. 9(b). For specimens stored in water, the flexural strength increases with increasing storage age but with a little ratios, while for specimens stored in sulfate, the flexural strength decreases with increasing storage age. The flexural strength for specimens stored in water is always higher than those stored in sulfate

The specimens stored in sulfate gives an opposite trend with increasing storage age (decreased with increasing storage age). This behavior is recorded for the plain, Fig. 9(a), and fiber reinforced mortar specimens, Fig. 9(b). The decrease in the flexural strength for specimens stored in sulfate with age can be explained as follow: The flexural strength is sensitive to the surface condition of the tension side of the beam. The sulfate attack leads to deterioration and formation of surface cavities, which act as local stress concentration sites and thus decreasing the failure load of the beam.

\section{Effect of Sulfate Resistant Cement (SRC)}

Figures 10, 11 and 12 show the effect of SRC on the compressive, tensile and flexural strengths of GFRM composite stored in water and sulfate media at $V_{f}$ equals $0 \%$, Figs. (a), and $V_{f}$ equals $2 \%$, Figs. (b). The general trend is that, all strengths of the un-reinforced and reinforced specimens stored in water increases with increasing storage age. For specimens stored in sulfate and reinforced by $2 \%$ glass fiber, the measured compressive strength increases up to storage age of 180 days, after that it decreased to a value less than that stored in water, as shown in Fig. 10(b).

This behavior may be attributed to the increase in the amount of voids in the specimens reinforced with fiber. This leads to large effect of sulfate compared to those without fibers where the compressive $s$ trength is a matrix control property. It is clear that SRC can prevent the attack of sulfate in control specimens $\left(\mathrm{V}_{\mathrm{f}}\right.$ $=0 \%$ ), as shown in Fig. 10(a).

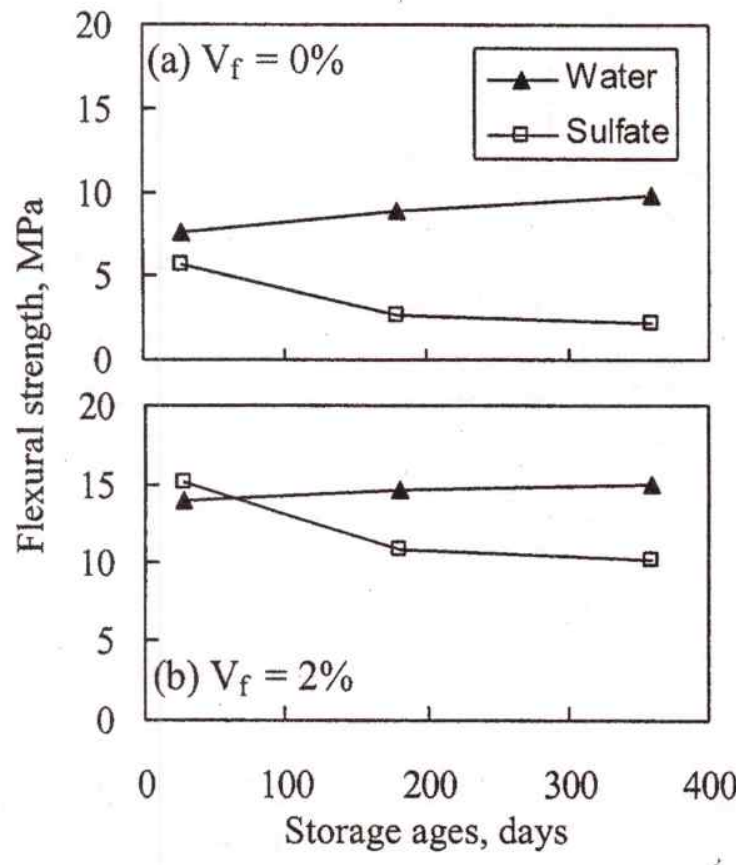

Fig.9 Flexural strength of GFRM composites against storage ages in presence of silica fume for:
(a) $\mathrm{V}_{\mathrm{f}}=0 \%$ and
(b) $\mathrm{V}_{\mathrm{f}}=2 \%$.

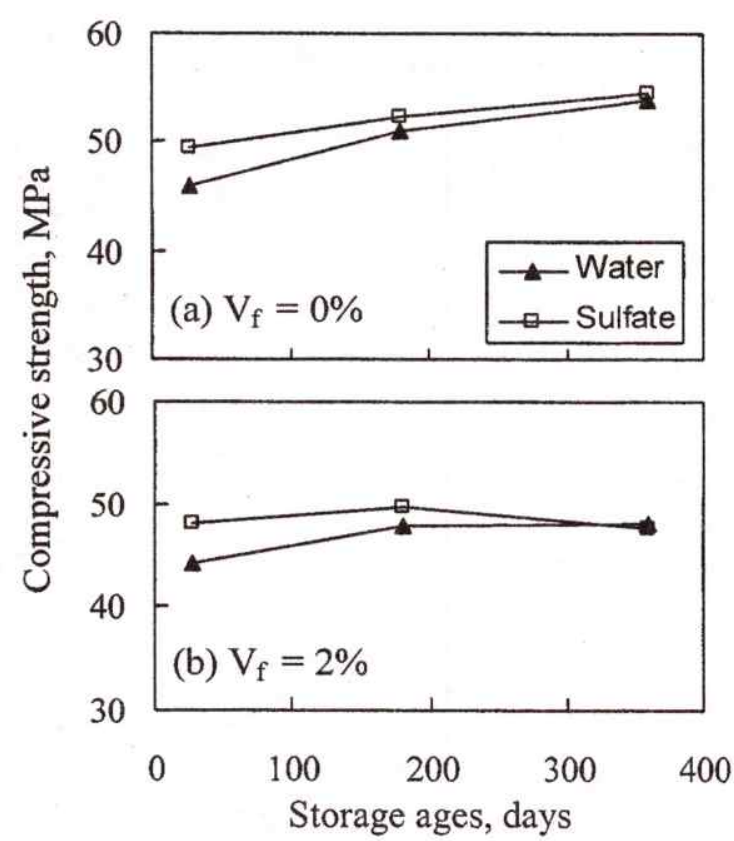

Fig.10 Compressive strength of GFRM composites made with SRC against storage ages for:
(a) $V_{f}=0 \%$ and
(b) $V_{f}=2 \%$. 


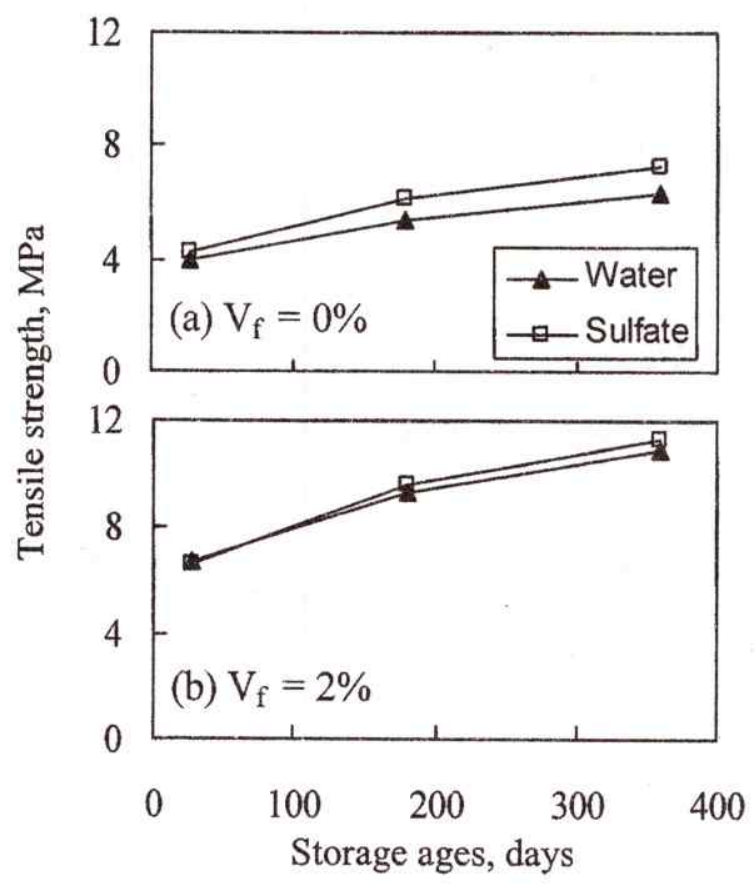

Fig.11 Tensile strength of GFRM composites made with SRC against storage ages for:
(a) $V_{f}=0 \%$ and
(b) $V_{f}=2 \%$.

The tensile strength increases with increasing storage age and there is no decrease in both water and sulfate media for un-reinforced and reinforced specimens as shown in Fig. 11a, and b. It is clear that SRC enhanced the behavior and the values of the tensile strength and resist sulfate attack. Fig. 12a and $\mathrm{b}$ shows the effect of SRC on the flexural strength of GFRM composite $s$ tored in water and sulfate media at $V_{f}$ equals $0 \%$, Fig. 12a, and $V_{f}$ equals $2 \%$, Fig. $12 \mathrm{~b}$.

The flexural strength increases with increasing storage age in water media for both un-reinforced and reinforced specimens. An opposite behavior was found for the specimens stored in sulfate, where the flexural strength decreases with increasing storage age. The Figures also show that the flexural strength for specimens stored in water is a lways higher than that stored in sulfate especially at $V_{f}=2 \%$.

\section{CONCLUSIONS}

The conclusions of this paper can be summarized as follows:

1- The compressive strength of GFRM specimens increased with increasing fiber volume fraction up to $1 \%$ for specimens stored in air, water and chloride. For specimens stored in sulfate, the compressive strength is almostely unchanged with fiber volume fraction.

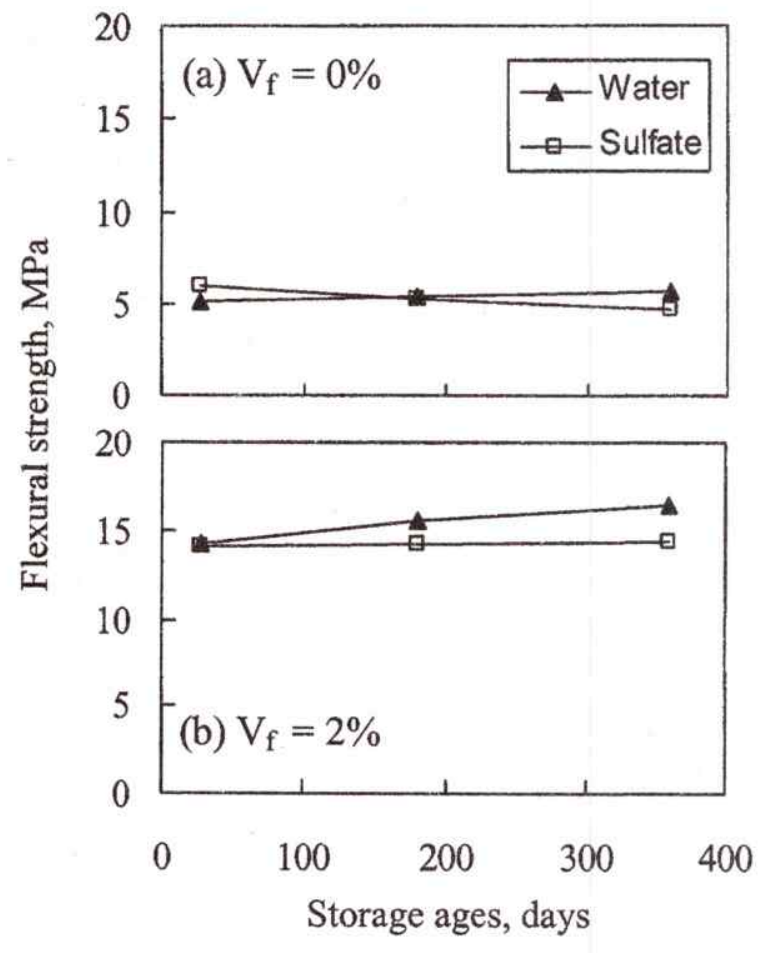

Fig.12 Flexural strength of GFRM composites made with SRC against storage ages for:
(a) $\mathrm{V}_{\mathrm{f}}=0 \%$ and
(b) $V_{f}=2 \%$.

2- The presence of glass fiber in the cement-based mortar enhanced the relative compressive strength of the composite stored in sulfate

3- The compressive strength increased with increasing storage age but with a marginal rate for specimens stored in sulfate, while the tensile and flexural strengths increased continuously with increasing storage age.

4- There is a general increase in the tensile and flexural strengths with increasing fiber volume fraction, $\mathrm{V}_{\mathrm{f}} \%$ for all storage media and storage ages.

5- The highest flexural strength was recorded for specimens stored in water for all storage ages and fiber volume fractions. The reinforced specimens stored in sulfate gave the lowest flexural strength up to storage age of 360 days irrespective of control specimens where, the specimens stored in chloride gave the lowest flexural strength.

6- At later ages and high fiber volume fraction, the effect of storage media on the flexural strength of the GFRM is approximately finished. At such condition, the behavior was controlled by the fiber.

7- The matrix strength is responsible for the composite compressive strength, while tensile and flexural strengths are controlled by fiber. 
8- The addition of $10 \%$ silica fume of cement weight enhanced the mechanical properties of the specimens stored in water media at all ages. For specimens stored in sulfate, the mechanical properties enhanced up to 180 days and after that they decreased.

9- Sulfate resistant cement specimens showed higher strength in sulfate media compared to those stored in water media especially in compressive and tensile strengths for un-reinforced specimens but it has a negative effect on the flexural strength.

\section{References}

[1] M. D. Cohen, and A. Bentur, "Durability of Portland Cement-Silica Fume Pastes in Magnesium Sulphate and Sodium Sulphate Solutions", ACI Materials Journal,Vol. 85, 1988, PP 148-157.

[2] O. S. B. Al-Amoudi, M. Maslehuddin, and M. M. S aadlem, "Effect of Magnesium Sulfate and Sodium Sulfate on the Durability Performance of Plain and Blended Cement", ACI Materials Journal, Vol. 92, 1995, PP 15-24.

[3] D. Bonen, "A Microstructural Study of the Effect Produced by Magnesium Sulfate on Plain and Silica Fume Bearing Portland Cement Mortars", Cement and Concrete Research, Vol. 23, 1993, PP 541-553.

[4] A. A. Amin, A. H. Ali, and H. El-Didamony, "Durability of Some P ortland C ement P astes in Various Chloride Solutions", Zement-KalkGips, Vol. 50, 1997, PP 172-177.

[5] H. Shehab, G. Ismail, S. Abdel-Megied, and I. Metwally, "Chemical Resistance of Concrete Containing Slag Cement and Silica Fume", Proceeding of Al-Azhar Eng., Sixth Inter. Conf, Vol. 3, 2000, PP 601-619.

[6] T. Fikret, A. Fevziye, K. Sema, and Y. Nabi, "Effects of Magnesium Sulfate Concentration on the Sulfate Resistance of Mortars With and Without Silica Fume", Cement and Concrete Research, Vol. 27, 1997, PP 205-214.

[7] Rasheeduzzafar, F. H. Dakhil, A. S. Al-Gahtani, S. S. A 1-Saadoun, and M. A. B ader, "Influence of Cement Composition on the Corrosion of Reinforcement and Sulphate Resistance of Concrete", ACI Materials Journal, Vol. 87, 1990, PP 114-122.

[8] E. F. Irassar, V. L. Bonavetti, and M. Gonzalez, "Microstructural Study of Sulfate Attack on
Ordinary and Limestone Portland Cements at Ambient Temperature", Cement and Concrete Research, Vol. 33, 2003, PP 31-41.

[9] A. A. M. Badawy, and S. S. E. Ahmad, "Sulphate Attack on Concrete From Mixing and Curing Water", Proceeding of Al-Azhar Eng., 7th Inter. Conf., 2003, CD code C02/01.

[10] M. H. Seleem, and A. A. M. Badawy, "Effect of Fiber Volume Fraction and Silica Fume Content on the Mechanical Properties of Cement Mortar", Proceeding of Al-Azhar Eng., Sixth Inter. Conf, Vol. 3, 2000, PP 545-554.

[11]A. A. M. Badawy, "Mechanical Behav-ior of High Strength Concrete Reinfor-ced With Glass Fiber", Military Technical College, International Conf. On Civil \& Arch. Eng., $4^{\text {th }}$ ICCAE Conf., Vol. 1, 2002, MQ4.

[12] W. Yao, J. Li, and K. Wu, "Mechanical Properties of Hybrid Fiber- Reinforced Concrete at Low Fiber Volume Fraction", Cement and Concrete Research, Vol. 33, 2003, PP 27-30.

[13]B. Singh, and A. J. Majumdar, "The Effect of Fiber Length and Content on the Durability of Glass Reinforced Cement-Ten Year Results", Journal of Materials Science, Vol. 4, 1985, PP 967-971.

[14] J. Bijen, "Durability of some Glass Fiber Reinforced Cement Composites", ACI Journal, Vol. 80, 1983, PP 305-311.

[15] S. Leonard, and A. Bentur, "Impro-vement of Durability of Glass Fiber Reinforced Cement Using Blended Cement Matrix", Cement and Concrete Research, Vol.14, 1984, pp. 717-728.

[16]A. Benture, "Silica Fume Treatments for Improving Durability of Glass Fiber Reinforced Cements", Journal of Materials in Civil Engineering, Vol. 1, 1989, PP 167- 183.

[17] K. Kosa, A. E. Naaman, and W. Hansen, "Durability of Fiber Reinforced Mortar" ACI Materials Journal, Technical Paper, Vol. 88, 1991, PP 310-319.

[18] D. J. Hannant, "Durability of Poly-propylene Fibers in Portland Cement-based Composites: eighteen years of data", Cement and Concrete Research, Vol.28, 1998, PP 1809-1817.

[19] J. Neil, and K. D. Ravindra, "Civil Engineering Materials", Fourth edition, Macmillan, 1990, PP 161-162. 